\title{
Pregnane Xenobiotic Receptors and Their Effect on Drug Elimination from the Organism
}

\section{Šíma M., Netíková I., Slanař O.}

Institute of Pharmacology, First Faculty of Medicine, Charles University in Prague and General University Hospital in Prague, Prague, Czech Republic

Received September 13, 2013; Accepted November 25, 2013.

Key words: Nuclear receptors - Pregnane xenobiotic receptors - Drug metabolism - Drug interactions

\begin{abstract}
Nuclear receptors are intracellular proteins which, having been activated by their more or less specific ligands, regulate (usually increase) the transcription of target genes. They thus participate in a regulation of a number of physiologic functions. Some of them - especially pregnane xenobiotic receptors serve primarily as protection of the organism from the xenobiotic intoxication. This is because many xenobiotics activate their function which consists in increasing the gene expression of enzymes involved in the metabolism of xenobiotics and detoxication drug transporters. Clarification of these mechanisms enabled the understanding of the substance of many drug-drug interactions observed in the clinical practice. Polymorphism of the nuclear receptors appears to be one of the causes of the interindividual variability in response to drug administration.
\end{abstract}

This study was supported by the Charles University Project PRVOUK P25/LF1/2.

Mailing Address: PharmDr. Martin Šíma, Institute of Pharmacology, First Faculty of Medicine, Charles University in Prague and General University Hospital in Prague, Albertov 4, 12800 Prague 2, Czech Republic; Phone: +420 224968 104; e-mail: sima.mart@seznam.cz 


\section{Nuclear receptors}

Nuclear receptors are involved in the superfamily of intracellular receptors (proteins). They are located either in the cytoplasm or in the nucleus. Having been activated by the ligand, they bind to specific spots on the DNA and work as transcription factors (they activate the gene transcription). By this mechanism, they regulate a wide range of physiologic functions, such as the ontogenesis, reproduction, differentiation, metabolism and homeostasis (Jacobs et al., 2003).

The selectivity of the effects, mediated by the nuclear receptors, as well as the possibility to regulate these effects, is given both by the affinity of particular ligands to particular receptors (some ligands activate a number of receptors, others act very specifically) and by the representation of particular receptors in particular tissues/organs. In addition, some receptors occur in more subtypes, while each subtype can be influenced by other ligands and can be located in other tissues, and thus mediate different effects (Mangelsdorf et al., 1992; Braissant et al., 1996; Harrington et al., 2003).

Nuclear receptors consist of 4-5 domains marked as A/B, C, D, E and F. These domains are often called with titles expressing their function. $A / B$ domain is called the modulator domain, $C$ as the DNA binding domain (DBD), $D$ domain forms a hinge region between the $C$ and $E$ domains, thus enabling taking various conformations, $\mathrm{E}$ is the ligand binding domain (LBD). The $\mathrm{F}$ domain is only present at some nuclear receptors, while it is lacking at the others. No other function of it has been described so far (Giguère, 1999; Bain et al., 2007).

Recently, a large number of nuclear receptors is known already, e.g. the steroid hormone receptors (AR - androgen receptors, ER - estrogen receptors, $\mathrm{PR}$ - progesterone receptors, MR - mineralcorticoid receptors, GR - glucocorticoid receptors), receptors of the thyroid gland hormones (TR), receptors for vitamin $D$ (VDR), constitutive androstane receptors (CAR), peroxisome proliferator activated receptors (PPAR), liver xenobiotic receptors $(L X R)$, farnesoid xenobiotic receptors (FXR), retinoid xenobiotic receptors ( $R X R)$, pregnane xenobiotic receptors (PXR) and many others (Germain et al., 2006).

\section{PXR (pregnane xenobiotic receptors)}

In 1998, Kliewer et al. described new nuclear receptors. With regards to their activation by many natural as well as synthetic progestins, they were named pregnane xenobiotic receptors (Kliewer et al., 1998). Before their title became generally accustomed, they used to be called "steroid and xenobiotic" receptors (SXR) or "pregnane-activated" receptors (PAR) in some works (Bertilsson et al., 1998; Blumberg et al., 1998). PXR are localized preliminarily in the liver and intestine, to a lesser extent they are expressed also in other tissues - e.g. in the kidney, lungs and stomach (Zhang et al., 1999). There is no consensus about the intracellular localization of PXR. Some works describe PXR occurrence in the nucleus only, regardless of whether they are in the state of activation by ligands 
or not (Koyano et al., 2004). Other works document cytoplasmic localization of PXR and their translocation to the nucleus, after their activation by the ligands (Kawana et al., 2003). PXR bind to DNA binding sequences (sometimes referred to as PXR-response elements) in the form of a heterodimer with RXR (Glass, 1994).

\section{PXR ligands}

Researches using SPA (scintillation proximity assay) and CARLA (coactivator receptor ligand assay) methods showed that PXR are activated by direct binding of ligand to the receptor (Krey et al., 1997; Lehmann et al., 1998; Jones et al., 2000).

PXR ligands include substances of both exogenous and endogenous origin, often very diverse in terms of their chemical structure - in size and shape of the molecule, as well as in chemical and physical-chemical properties. As a ligand, binding to human PXR, was described e.g. pregnenolone and its metabolites (the strongest PXR activator of them is $5 \beta$-pregnane-3,20-dione), vitamin $E$ (especially $\gamma$-tocotrienol is responsible for its effect), 9-cis retinoic acid, hyperforin (content substance of the St. John's wort extract, used as antidepressant) and many other drugs (cyproterone acetate, dexamethasone, phenobarbital, clotrimazole, mifepristone, rifampicin, ritonavir, spironolactone, tamoxifen, troglitazone). As the strongest PXR activator has so far been described SR12813 (tetraethyl 2-(3,5-di-tertbutyl-4-hydroxyphenyl)ethenyl-1,1-bisphosphonate) (Lehmann et al., 1998; Jones et al., 2000; Wentworth et al., 2000; Dussault et al., 2001; Desai et al., 2002; Zhou et al., 2004). No other so far known nuclear receptors show such a diversity of ligands. For this reason, and in connection with a large number of biotransformation enzymes and detoxifying drug transporters that they influence (see below), PXR are considered a key factor in the system of organism protection against xenobiotic intoxication or high level of endogenous substances (Orans et al., 2005).

Unlike most other nuclear receptors, PXR show significant interspecies differences in the LBD sequence (less than 80 percent of sequence homology in the LBD, in comparison with more than 95 percent of sequence homology in the DBD). This results in different regulation of target structures transcription in various species, as a response to diverse extent of activation by the same ligand. For instance rifampicin is a strong PXR activator in humans and rabbits, while the mouse and rat PXR activates only slightly. On the contrary, PCN (pregnenolone$16 \alpha$-carbonitrile) strongly activates PXR of mice and rats, on PXR of humans and rabbits it affects very weakly, though (Jones et al., 2000; Orans et al., 2005). Different enantiomers of the same optically active compound can also cause different extent of PXR activation in various species. Well-described is e.g. PXR activation by the substance S20 (chemically C-cyclopropylalkylamide), where (-)-S20 enantiomer is a strong PXR activator in mice and weak PXR activator in humans, while (+)-S20 activates strongly human PXR and weakly the mouse one (Mu et al., 2005). 
Occupying PXR by ligand is a significant but not the sole factor determining the transcription activity of PXR. That is complicatedly regulated by many others, so-called epigenetic factors. PXR interact with coregulators (e.g. steroid/nuclear receptor coactivator SRC-1, hepatocyte nuclear factor HNF-4 $\alpha$ and protein arginine methyltransferase PRMT1), which affect chromatine modification of DNA, thus making the binding spots for PXR either accessible or inaccessible. Also the posttranslational modification of PXR regulates their resulting activity. There was described e.g. acetylation, phosphorylation, ubiquitination and sumoylation (Staudinger et al., 2011; Tian, 2013).

\section{PXR-mediated regulation of xenobiotics eliminating structures}

Binding spots for PXR, the so-called PXR response elements were observed in promoter areas of many genes, coding the enzymes of I. and II. phases of drug metabolism, as well as detoxification transport proteins. In humans, PXR regulate the transcription of genes for CYP3A, CYP2C, CYP2B and CYP7A enzyme subfamilies, glutathione-S-transferase and MRP1, MRP2 (multidrug resistanceassociated protein 1 and 2) and OATP (organic anion-transporting polypeptide) transporters (Lehmann et al., 1998; Fromm et al., 2000; Goodwin et al., 2001; Li and Chiang, 2005; Chen and Goldstein, 2009; Svoboda et al., 2011). Crucial significance for drug elimination from the organism has especially the PXR-mediated induction of enzymes CYP3A4, CYP2C9, CYP2C19, CYP2B6 (I. metabolism phase) and glutathione-S-transferase (II. metabolism phase), as well as the MRP1 transporter, known as P-glycoprotein (Wang et al., 2012). In addition, PXR are involved in metabolism regulation and in excretion of cholesterol and bile acids, where the key role plays inhibition of CYP7A1 gene expression and induction of OATP2 and MRP2 transporters gene expression (Jonker et al., 2012). PXR are also involved in regulation of energetic metabolism (Wada et al., 2009).

In mice, partial function overlap of PXR and CAR has been observed. Both receptors have some common ligands and both participate in expression regulation of some genes, too. Specifically e.g. phenobarbital is an activating ligand of both PXR and CAR. Having been activated by phenobarbital, both these receptors bind to the same binding spots on DNA in the promoter areas of genes for not only CYP3A, but also CYP2B enzyme subfamily, thus activating their transcription (Xie et al., 2000).

In humans, there was described a synergistic effect of glucocorticoid receptors, increasing the PXR-mediated activation of gene transcription. E.g. dexamethasone induces CYP3A4 even in low concentrations which are not sufficient for PXR activation, but which activate GR. It has been found out that GR, after activation, increase the expression of genes for PXR and CAR, and these receptors then mediate induction of CYP3A4 (Pascussi et al., 2001). By this mechanism, dexamethasone induces also CYP2B6. By administering dexamethasone in low concentration (which does not activate PXR but does activate GR) together 
with some PXR activators (rifampicin, phenobarbital, phenytoin, clotrimazole), it resulted in significant increase of induction of CYP2B6, as opposed to administering the ligand alone (rifampicin, phenobarbital, phenytoin, clotrimazole) without dexamethasone (Wang et al., 2003).

The above stated implies that regulatory mechanisms resulting in xenobiotic elimination are complex, and signalling pathways of nuclear receptors are mutually intersected.

\section{Polymorphisms of PXR, interindividual variability of CYP3A4}

Enzyme CYP3A4 is regarded as the main isoform of cytochrome P450, involved in drug metabolism. It is stated that it participates in metabolism of more than half of the drugs used in clinical practice (Schuetz, 2004). There were described multiple interindividual differences in expression of this isoform in human liver, as well as in clearance of model drugs metabolised using CYP3A4 (midazolam) (Lamba et al., 2002; Floyd et al., 2003). This individual variability in activity of CYP3A4 is attributed to genetic polymorphism (Ozdemir et al., 2000). Nonetheless, there were discovered spot mutations (SNP - single nucleotide polymorphism) in both regulatory and coding areas of the gene for CYP3A4 which do not correlate with the degree of expression and function of CYP3A4. That is why they are unlikely to be the cause of the above mentioned variability (Eichelbaum and Burk, 2001; Lamba et al., 2002; Schuetz, 2004).

A possible explanation offers the polymorphism of $P X R$, main regulators of CYP3A4 expression. Many SNP were found in the gene for human PXR, however, only some of them were of the missense type (i.e. leading to substitution of the amino acid in the primary structure of PXR). In comparison with the wild type allele, at four of these mutations a change of phenotype of CYP3A4 occurred, both in the state of basal activity and after induction evoked by rifampicin. Specifically, these are PXR polymorphisms V140M, D163G, A370T and R122Q. Allele R122Q, which alters an amino acid in the DBD of PXR, leads to decreasing the affinity of ligand-activated PXR to the binding spot on DNA. This results in a decrease of the transcription activity of PXR. Alleles V140M, D163G and A370T result in alteration of amino acid in the LBD of receptors. While D163G causes a decrease in the activity compared to the wild type allele, V140M and A370T increase the transcription activity (Hustert et al., 2001; Zhang et al., 2001; Zhang et al., 2008). Nevertheless, it shows that PXR polymorphism is not the only factor causing interindividual variability of CYP3A4 in population (Wang and LeCluyse, 2003). With regards to complexity of the processes leading to elimination of xenobiotics, more structures involved in the signalling cascades are expected to contribute partially to interindividual variability of activity of CYP3A4. 


\section{Consequence of drug-induced activation of PXR in clinical practice}

As it was mentioned, many drugs used in the clinical practice activate PXR. These, as the main regulatory element of xenobiotic elimination, then increase gene expression of enzymes involved in drug metabolism (CYP3A4, CYP2C9, CYP2C19, CYP2B6), and of detoxification drug transporters (MRP1, MRP2). This way, it can thus lead to drug interactions with a wide range of drugs.

As strong enzyme inductors are considered e.g. the antituberculotic drug rifampicin and the anticonvulsants phenobarbital, phenytoin and carbamazepine. At all of these substances, PXR activation is considered as a cause of the enzyme induction (Cui et al., 2008). If other drugs are administered concurrently with them, whose clearance is substantially dependant on the above mentioned structures (CYP3A4, CYP2C9, CYP2C19, CYP2B6, MRP1, MRP2), it results in significant decrease of their plasmatic concentrations. This can lead to failure of pharmacotherapy.

On the contrary, if the drug is administered in the form of a prodrug, which metabolises to its active form using the above mentioned enzymes, PXR activators can increase the toxicity of these drugs by means of enzyme induction. E.g. cyclophosphamide (alkylating cytostatics and immunosuppressive) and iphosphamide (alkylating cytostatics) are metabolised using isoenzymes CYP3A4 and CYP2B6 in the body. Induction of these enzymes results in increased metabolism of cyclophosphamide and iphosphamide to 4-hydroxylated derivatives responsible for their therapeutic effect but also in increasing the plasmatic concentrations of $\mathrm{N}$-dechloroethylated metabolites that have a strong neurotoxic effect (Huang et al., 2000; Wang and LeCluyse, 2003).

Drug interaction is defined as a change of effect of one drug caused by another, concurrently administered drug. When a drug increases its own clearance, it is called auto-induction. This happens in the case when the drug is an activating PXR ligand and at the same time, it is a substrate of structures whose expression is increased by PXR. E.g. phenytoin, using PXR, induces (among others) isoenzyme CYP2C9, by which it extensively metabolises, thus decreasing its own concentration in the plasma (Chetty et al., 1998). Similarly carbamazepine, as an inductor and substrate of isoenzyme CYP3A4, accelerates its metabolism which manifests through the decrease of its plasmatic concentration (Scheyer et al., 1994).

In pursuit of avoiding the risk of drug interactions, many working groups in drug research and development deal with the possibility of achieving the decrease of PXR activation by modification of structure of the drug that is being developed. It shows that decreasing the interaction between the ligand and the DBD of PXR can be reached by introducing polar groups into the ligand molecule, and by removing, or steric hindrance, of the function group creating the hydrogen binding with the LBD of PXR. These structural modifications in the molecule of the ligand - potential drug - often result in changing its effect, toxicity and pharmacokinetics, though (Sinz, 2013). 


\section{Conclusion}

PXR are intracellular proteins which, having been activated by their ligands, regulate the expression of drug-metabolising enzymes and transporting proteins. If the above mentioned ligand is a drug, it can result in drug-drug interactions in the sense of increased elimination of the concurrently administered drugs, alternatively even in increased elimination of the drug itself. Polymorphisms of PXR appear to be one of the causes of interindividual variability in response to drug administration. Our knowledge of this field is still limited. Further research is needed to clarify the details of the above mentioned mechanisms and their importance for drug-drug interactions manifestation.

\section{References}

Bain, D. L., Heneghan, A. F., Connaghan-Jones, K. D., Miura, M. T. (2007) Nuclear receptor structure: implications for function. Annu. Rev. Physiol. 69, 201-220.

Bertilsson, G., Heidrich, J., Svensson, K., Asman, M., Jendeberg, L., Sydow-Bäckman, M., Ohlsson, R., Postlind, H., Blomquist, P., Berkenstam, A. (1998) Identification of a human nuclear receptor defines a new signaling pathway for CYP3A induction. Proc. Natl. Acad. Sci. USA 95(21), 12208-12213.

Blumberg, B., Sabbagh, W., Juguilon, H., Bolado, J., van Meter, C. M., Ong, E. S., Evans, R. M. (1998) SXR, a novel steroid and xenobiotic-sensing nuclear receptor. Genes Dev. 12(20), 3195-3205.

Braissant, O., Foufelle, F., Scotto, C., Dauça, M., Wahli, W. (1996) Differential expression of peroxisome proliferator-activated receptors (PPARs): tissue distribution of PPAR-alpha, -beta, and -gamma in the adult rat. Endocrinology 137(1), 354-366.

Chen, Y., Goldstein, J. A. (2009) The transcriptional regulation of the human CYP2C genes. Curr. Drug Metab. 10(6), 567-578.

Chetty, M., Miller, R., Seymour, M. A. (1998) Phenytoin auto-induction. Ther. Drug Monit. 20(1), 60-62.

Cui, X., Thomas, A., Gerlach, V., White, R. E., Morrison, R. A., Cheng, K. C. (2008) Application and interpretation of hPXR screening data: Validation of reporter signal requirements for prediction of clinically relevant CYP3A4 inducers. Biochem. Pharmacol. 76(5), 680-689.

Desai, P. B., Nallani, S. C., Sane, R. S., Moore, L. B., Goodwin, B. J., Buckley, D. J., Buckley, A. R. (2002) Induction of cytochrome P450 3A4 in primary human hepatocytes and activation of the human pregnane $X$ receptor by tamoxifen and 4-hydroxytamoxifen. Drug Metab. Dispos. 30(5), 608-612.

Dussault, I., Lin, M., Hollister, K., Wang, E. H., Synold, T. W., Forman, B. M. (2001) Peptide mimetic HIV protease inhibitors are ligands for the orphan receptor SXR. J. Biol. Chem. 276(36), 33309-33312.

Eichelbaum, M., Burk, O. (2001) CYP3A genetics in drug metabolism. Nat. Med. 7(3), 285-287.

Floyd, M. D., Gervasini, G., Masica, A. L., Mayo, G., George, A. L., Bhat, K., Kim, R. B., Wilkinson, G. R. (2003) Genotype-phenotype associations for common CYP3A4 and CYP3A5 variants in the basal and induced metabolism of midazolam in European- and African-American men and women. Pharmacogenetics 13(10), 595-606.

Fromm, M. F., Kauffmann, H. M., Fritz, P., Burk, O., Kroemer, H. K., Warzok, R. W., Eichelbaum, M., Siegmund, W., Schrenk, D. (2000) The effect of rifampin treatment on intestinal expression of human MRP transporters. Am. J. Pathol. 157(5), 1575-1580.

Germain, P., Staels, B., Dacquet, C., Spedding, M., Laudet, V. (2006) Overview of nomenclature of nuclear receptors. Pharmacol. Rev. 58(4), 685-704.

Giguère, V. (1999) Orphan nuclear receptors: from gene to function. Endocr. Rev. 20(5), 689-725.

Glass, C. K. (1994) Differential recognition of target genes by nuclear receptor monomers, dimers, and heterodimers. Endocr. Rev. 15(3), 391-407. 
Goodwin, B., Moore, L. B., Stoltz, C. M., McKee, D. D., Kliewer, S. A. (2001) Regulation of the human CYP2B6 gene by the nuclear pregnane $X$ receptor. Mol. Pharmacol. 60(3), 427-431.

Harrington, W. R., Sheng, S., Barnett, D. H., Petz, L. N., Katzenellenbogen, J. A., Katzenellenbogen, B. S. (2003) Activities of estrogen receptor alpha- and beta-selective ligands at diverse estrogen responsive gene sites mediating transactivation or transrepression. Mol. Cell. Endocrinol. 206(1-2), 13-22.

Huang, Z., Roy, P., Waxman, D. J. (2000) Role of human liver microsomal CYP3A4 and CYP2B6 in catalyzing $\mathrm{N}$-dechloroethylation of cyclophosphamide and ifosfamide. Biochem. Pharmacol. 59(8), 961-972.

Hustert, E., Zibat, A., Presecan-Siedel, E., Eiselt, R., Mueller, R., Fuss, C., Brehm, I., Brinkmann, U., Eichelbaum, M., Wojnowski, L., Burk, O. (2001) Natural protein variants of pregnane $X$ receptor with altered transactivation activity toward CYP3A4. Drug Metab. Dispos. 29(11), 1454-1459.

Jacobs, M. N., Dickins, M., Lewis, D. F. (2003) Homology modelling of the nuclear receptors: human oestrogen receptorbeta (hERbeta), the human pregnane-X-receptor (PXR), the Ah receptor (AhR) and the constitutive androstane receptor (CAR) ligand binding domains from the human oestrogen receptor alpha (hERalpha) crystal structure, and the human peroxisome proliferator activated receptor alpha (PPARalpha) ligand binding domain from the human PPARgamma crystal structure. J. Steroid Biochem. Mol. Biol. 84(2-3), 117-132.

Jones, S. A., Moore, L. B., Shenk, J. L., Wisely, G. B., Hamilton, G. A., McKee, D. D., Tomkinson, N. C., LeCluyse, E. L., Lambert, M. H., Willson, T. M., Kliewer, S. A., Moore, J. T. (2000) The pregnane X receptor: a promiscuous xenobiotic receptor that has diverged during evolution. Mol. Endocrinol. 14(1), 27-39.

Jonker, J. W., Liddle, C., Downes, M. (2012) FXR and PXR: potential therapeutic targets in cholestasis. J. Steroid Biochem. Mol. Biol. 130(3-5), 147-158.

Kawana, K., Ikuta, T., Kobayashi, Y., Gotoh, O., Takeda, K., Kawajiri, K. (2003) Molecular mechanism of nuclear translocation of an orphan nuclear receptor, SXR. Mol. Pharmacol. 63(3), 524-531.

Kliewer, S. A., Moore, J. T., Wade, L., Staudinger, J. L., Watson, M. A., Jones, S. A., McKee, D. D., Oliver, B. B., Willson, T. M., Zetterström, R. H., Perlmann, T., Lehmann, J. M. (1998) An orphan nuclear receptor activated by pregnanes defines a novel steroid signaling pathway. Cell 92(1), 73-82.

Koyano, S., Kurose, K., Saito, Y., Ozawa, S., Hasegawa, R., Komamura, K., Ueno, K., Kamakura, S., Kitakaze, M., Nakajima, T., Matsumoto, K., Akasawa, A., Saito, H., Sawada, J. (2004) Functional characterization of four naturally occurring variants of human pregnane $X$ receptor (PXR): one variant causes dramatic loss of both DNA binding activity and the transactivation of the CYP3A4 promoter/enhancer region. Drug Metab. Dispos. 32(1), 149-154.

Krey, G., Braissant, O., L’Horset, F., Kalkhoven, E., Perroud, M., Parker, M. G., Wahli, W. (1997) Fatty acids, eicosanoids, and hypolipidemic agents identified as ligands of peroxisome proliferator-activated receptors by coactivator-dependent receptor ligand assay. Mol. Endocrinol. 11(6), 779-791.

Lamba, J. K., Lin, Y. S., Schuetz, E. G., Thummel, K. E. (2002) Genetic contribution to variable human CYP3A-mediated metabolism. Adv. Drug Deliv. Rev. 54(10), 1271-1294.

Lehmann, J. M., McKee, D. D., Watson, M. A., Willson, T. M., Moore, J. T., Kliewer, S. A. (1998) The human orphan nuclear receptor PXR is activated by compounds that regulate CYP3A4 gene expression and cause drug interactions. J. Clin. Invest. 102(5), 1016-1023.

$\mathrm{Li}, \mathrm{T}$. , Chiang, J. Y. (2005) Mechanism of rifampicin and pregnane X receptor inhibition of human cholesterol 7 alpha-hydroxylase gene transcription. Am. J. Physiol. Gastrointest. Liver Physiol. 288(1), G74-G84.

Mangelsdorf, D. J., Borgmeyer, U., Heyman, R. A., Zhou, J. Y., Ong, E. S., Oro, A. E., Kakizuka, A., Evans, R. M. (1992) Characterization of three RXR genes that mediate the action of 9-cis retinoic acid. Genes Dev. 6(3), 329-344.

Mu, Y., Stephenson, C. R., Kendall, C., Saini, S. P., Toma, D., Ren, S., Cai, H., Strom, S. C., Day, B. W., Wipf, P., Xie, W. (2005) A pregnane $X$ receptor agonist with unique species-dependent stereoselectivity and its 
implications in drug development. Mol. Pharmacol. 68(2), 403-413.

Orans, J., Teotico, D. G., Redinbo, M. R. (2005) The nuclear xenobiotic receptor pregnane X receptor: recent insights and new challenges. Mol. Endocrinol. 19(12), 2891-2900.

Ozdemir, V., Kalow, W., Tang, B. K., Paterson, A. D., Walker, S. E., Endrenyi, L., Kashuba, A. D. (2000) Evaluation of the genetic component of variability in CYP3A4 activity: a repeated drug administration method. Pharmacogenetics 10(5), 373-388.

Pascussi, J. M., Drocourt, L., Gerbal-Chaloin, S., Fabre, J. M., Maurel, P., Vilarem, M. J. (2001) Dual effect of dexamethasone on CYP3A4 gene expression in human hepatocytes. Sequential role of glucocorticoid receptor and pregnane $X$ receptor. Eur. J. Biochem. 268(24), 6346-6358.

Scheyer, R. D., Cramer, J. A., Mattson, R. H. (1994) A pharmacodynamic approach to the estimate of carbamazepine autoinduction. J. Pharm. Sci. 83(4), 491-494.

Schuetz, E. G. (2004) Lessons from the CYP3A4 promoter. Mol. Pharmacol. 65(2), 279-281.

Sinz, M. W. (2013) Evaluation of pregnane X receptor (PXR)-mediated CYP3A4 drug-drug interactions in drug development. Drug Metab. Rev. 45(1), 3-14.

Staudinger, J. L., Xu, C., Biswas, A., Mani, S. (2011) Post-translational modification of pregnane $\mathrm{x}$ receptor. Pharmacol. Res. 64(1), 4-10.

Svoboda, M., Riha, J., Wlcek, K., Jaeger, W., Thalhammer, T. (2011) Organic anion transporting polypeptides (OATPs): regulation of expression and function. Curr. Drug Metab. 12(2), 139-153.

Tian, Y. (2013) Epigenetic regulation of pregnane X receptor activity. Drug Metab. Rev. 45(2), 166-172.

Wada, T., Gao, J., Xie, W. (2009) PXR and CAR in energy metabolism. Trends Endocrinol. Metab. 20(6), 273-279.

Wang, H., LeCluyse, E. L. (2003) Role of orphan nuclear receptors in the regulation of drug-metabolising enzymes. Clin. Pharmacokinet. 42(15), 1331-1357.

Wang, H., Faucette, S. R., Gilbert, D., Jolley, S. L., Sueyoshi, T., Negishi, M., LeCluyse, E. L. (2003) Glucocorticoid receptor enhancement of pregnane $\mathrm{X}$ receptor-mediated CYP2B6 regulation in primary human hepatocytes. Drug Metab. Dispos. 31(5), 620-630.

Wang, Y. M., Ong, S. S., Chai, S. C., Chen, T. (2012) Role of CAR and PXR in xenobiotic sensing and metabolism. Expert Opin. Drug Metab. Toxicol. 8(7), 803-817.

Wentworth, J. M., Agostini, M., Love, J., Schwabe, J. W., Chatterjee, V. K. (2000) St. John's wort, a herbal antidepressant, activates the steroid $X$ receptor. J. Endocrinol. 166(3), R11-R16.

Xie, W., Barwick, J. L., Simon, C. M., Pierce, A. M., Safe, S., Blumberg, B., Guzelian, P. S., Evans, R. M. (2000) Reciprocal activation of xenobiotic response genes by nuclear receptors SXR/PXR and CAR. Genes Dev. 14(23), 3014-3023.

Zhang, B., Xie, W., Krasowski, M. D. (2008) PXR: a xenobiotic receptor of diverse function implicated in pharmacogenetics. Pharmacogenomics 9(11), 1695-1709.

Zhang, H., LeCulyse, E., Liu, L., Hu, M., Matoney, L., Zhu, W., Yan, B. (1999) Rat pregnane X receptor: molecular cloning, tissue distribution, and xenobiotic regulation. Arch. Biochem. Biophys. 368(1), 14-22.

Zhang, J., Kuehl, P., Green, E. D., Touchman, J. W., Watkins, P. B., Daly, A., Hall, S. D., Maurel, P., Relling, M., Brimer, C., Yasuda, K., Wrighton, S. A., Hancock, M., Kim, R. B., Strom, S., Thummel, K., Russell, C. G., Hudson, J. R., Schuetz, E. G., Boguski, M. S. (2001) The human pregnane $X$ receptor: genomic structure and identification and functional characterization of natural allelic variants. Pharmacogenetics 11(7), 555-572.

Zhou, C., Tabb, M. M., Sadatrafiei, A., Grün, F., Blumberg, B. (2004) Tocotrienols activate the steroid and xenobiotic receptor, SXR, and selectively regulate expression of its target genes. Drug Metab. Dispos. 32(10), 1075-1082. 